\title{
LETRAMENTO ACADÊMICO PARA SURDOS: REFLEXÕES CONTEMPORÂNEAS
}

\author{
Maria Clara Maciel de A. Ribeiro \\ mclaramaciel@hotmail.com \\ Universidade Estadual de Montes Claros
}

RESUMO: Este estudo discute a entrada de surdos na universidade e a produção acadêmico-científica decorrente dela com o objetivo de evidenciar a necessidade de se pensar em cursos de português que contemplem uma proposta de Letramento Acadêmico para surdos usuários de português como segunda língua que sejam estudantes de pósgraduação stricto sensu. Inicialmente, o estudo considera a produção acadêmica de sujeitos surdos como representante de um modelo de racionalidade científica emergente e, em seguida, elenca suas características. Posteriormente, a partir da proposição de eixos de ensino norteadores, a saber, o eixo das facetas acadêmicas e ativistas; o eixo do gerenciamento de vozes; o eixo normativo-metodológico e o eixo da estrutura da Língua Portuguesa, apresentam-se os pilares de sustentação de uma proposta de ensino que considere a Língua Portuguesa escrita como o pilar emancipatório na formação de pesquisadores surdos.

PALAVRAS-CHAVE: surdos; língua portuguesa; letramento acadêmico.

\section{ACADEMIC LITERACY FOR DEAF STUDENTS: CONTEMPORARY REFLECTIONS}

\begin{abstract}
This study discusses the entry of deaf students at graduate school and their academic-scientific production. It aims to bring attention to the need to think, at the University, of Portuguese courses that contemplate a proposal of Academic Literacy for deaf graduate students, users of Portuguese as a second language. From the proposition of guiding teaching axes, namely, the axis of academic and activist facets; the axis of voice management; the normative and methodological axis and the axis of Portuguese structure present the supporting pillars of a proposal that considers the Portuguese language as the emancipatory pillar in the formation of deaf researchers.
\end{abstract}

KEYWORDS: deaf; Portuguese; academic literacy. 


\section{Introdução}

Há algum tempo, expressões como professor surdo ou surdo doutor poderiam constar em um manual de semântica como exemplos de expressões anômalas e/ou contraditórias do ponto de vista semântico. Não se julgava possível - ou não se permitia - que um cidadão que não ouvisse, e que se expressasse por uma língua de modalidade distinta da padrão, pudesse atingir níveis de desenvolvimento cognitivo considerados elevados. Atualmente, contudo, vê-se um número crescente de surdos Mestres e Doutores e, se por um lado, já não existem dúvidas quanto à capacidade cognitiva daqueles que se expressam em sinais, por outro, surgem dúvidas e questionamentos de outra natureza, derivados agora da relação de sobreposição de línguas ${ }^{1}$, fazeres e lugares sociais expressos no bojo de pesquisas acadêmicas empreendidas por pesquisadores surdos (RIBEIRO, 2012).

A partir da focalização da relação surdos versus fazeres acadêmicos, entre diversos questionamentos possíveis, este estudo se preocupa com um, especificamente, apesar de tangenciar em superfície outros: discute-se aqui a produção acadêmica empreendida por surdos com vistas a evidenciar a necessidade de se pensar em cursos de português para este específico fim: letramento acadêmico para surdos usuários de português como segunda língua.

Para tanto, penso, primeiramente, nas especificidades da produção acadêmica de autoria surda (como a influência do Movimento Surdo) e, em seguida, vislumbro uma proposta de letramento acadêmico para surdos graduandos e pós-graduandos. Este estudo considera que ascender o debate sobre o tema pode ser o primeiro passo para a eventual proposição de um programa nacional de letramento acadêmico para surdos que considere a língua portuguesa como pilar emancipatório na formação acadêmica desses sujeitos.

Alerto que o interesse deste artigo é discutir a chegada da população surda à universidade e as ações de pesquisa acadêmica empreendidas por ela, com vistas a entender o quê, exatamente, precisa constar em programas de letramento acadêmico para surdos, assim como os porquês dessa proposição. Assim, aos leitores interessados, especificamente, na temática do letramento acadêmico, remeto-os às obras de Street (1984) e Lea \& Street (1998), referências fundamentais na temática.

\footnotetext{
${ }^{1}$ Falamos, aqui, das influências e (inter)relações entre a Língua Portuguesa e a Língua Brasileira de Sinais, no momento da construção do conhecimento pelo sujeito surdo. Apesar das pesquisas serem apresentadas em português escrito, certamente elas são cognitivamente construídas em sinais.
}

Olh@res, Guarulhos, v. 4, n. 1, p. 269-286, maio 2016. 


\section{O sujeito, a língua e os movimentos sociais}

As humanidades conhecem e reconhecem estudos científicos sobre línguas visuais desde o início da década de sessenta do século passado (STOKOE, 1960). No entanto, os desdobramentos massivos desse conhecimento - como o fato da língua sinalizada constituir o sujeito surdo a partir do "lugar" de primeira língua ou o reconhecimento de processos culturais e identitários advindos dessa condição linguística, junto à certeza de a modalidade da língua (visual) não interferir negativamente nos processos cognitivos só começaram a beneficiar socioeducacionalmente os sujeitos surdos a partir da década de oitenta. No Brasil, para sermos mais exatos, pode-se alterar essa data para o início dos anos dois mil, se considerarmos os efeito advindos das políticas públicas nacionais.

Tem-se, portanto, como bastante recente a compreensão acadêmico-científica de vida social e educativa desenvolvida a partir de um estado de compreensão e expressão visual. Tanto é que as marcas de um passado opressor e assistencialista ainda se fazem presentes na memória discursiva de muitos surdos, como afirmam Ribeiro e Lara (2010). Além disso, em espaços longínquos e interioranos, ainda é muito frequente encontrar surdos com nenhuma ou pouca escolaridade, sendo tratados como "doentes" ou “incapacitados". Na maioria dos casos, esses sujeitos e suas famílias desconhecem tanto a Libras padrão (comunicam-se a partir do estabelecimento de "sinais caseiros") quanto o discurso moderno sobre o ser surdo, o que acaba por conduzi-los a aceitação de estereotipias distorcidas e preconceituosas sobre a condição de vida surda.

Nos médios e grandes centros urbanos, contudo, as comunidades surdas costumam se mobilizar em Associações de Surdos e, dessa coesão, surge o sentimento de pertencimento a uma nação imaginária, com língua e cultura comuns. Desse sentimento surge o desejo de ampliarem sua participação social frente à presença hegemônica

ouvinte. É assim que agora politizados e movidos por discussões intelectualizadas sobre o $e$ e e o outro nas esferas sociais, surdos dão vazão ao chamado Movimento Surdo - um movimento social de resistência que reivindica melhorias educacionais, sociais e até mesmo imagéticas para os cidadãos surdos.

Sustento, portanto, sem sombra de dúvida, que se hoje discutimos o ingresso de surdos na graduação e pós-graduação brasileira isso se deve, em grande medida, ao empenho e organização das comunidades surdas que, em defesa de sua língua e da preservação de seus direitos, projetaram-se socialmente a partir do chamado Movimento Surdo.

De acordo com Dall’Alba (2012), os primeiros Movimentos Surdos no mundo dos Olh@res, Guarulhos, v. 4, n. 1, p. 269-286, maio 2016. 
quais se têm notícias foram motivados pelas práticas de normalização impostas pelos ouvintes (como aconteceu na França, no século XVIII). Entende-se por "práticas de normalização" as tentativas de ensinar surdos a se "tornarem" ouvintes, copiando modelos e padrões hegemônicos em detrimento, muitas vezes, de sua própria língua e cultura.

Consta-se, por exemplo, que, por volta de 1760, um movimento de surdos de resistência contra a ideologia verbal (ensino da fala) já começava a se delinear no Instituto Nacional de Surdos-Mudos de Paris, como informa Lodi (2004). Tudo indica que junto às primeiras escolas para surdos, ainda no século XVIII, surgiram também as primeiras manifestações contra as imposições dos ouvintes, pois a partir do momento em que os surdos se viram reunidos e se descobriram semelhantes, o sentimento de força e união propiciou a iniciativa reivindicatória. Parece, portanto, que o desejo de que os surdos deixassem de ser surdos, ou, pelo menos, de que "tratassem a surdez", sempre partiu dos ouvintes. Parece, também, que a mobilização popular e a iniciativa reivindicatória, na comunidade surda, não recebem influência determinante externa (ouvinte), porque germina e floresce na própria comunidade.

No Brasil, considera-se como marco fortalecedor do Movimento Surdo a ocasião em que, em 1987, a chamada Feneida (Federação Nacional de Educação e Integração dos Deficientes Auditivos), fundada e mantida por ouvintes desde 1977, passa a se denominar Feneis (Federação Nacional de Educação e Integração dos Surdos) e a ser composta e dirigida por sujeitos surdos. A partir daí, surgem filiais com diretoria surda em diversos estados brasileiros e observa-se uma drástica mudança nas formas de abordar e conduzir as causas surdas nacionais (RANGEL, 2010).

Em nosso país, a adesão ao Movimento Surdo já esteve restrita aos principais estados brasileiros. Atualmente, contudo, assiste-se a uma intensa mobilização nacional que abarca sem exceção todos os estados brasileiros, de norte a sul do país. Na era da informação, cada vez mais surdos, de todos os cantos do país, expressam publicamente seu sentimento de pertencimento à causa surda, seja através da divulgação de vídeos de manifestos on-line, seja por meio da publicação de textos em português em blogs ativistas.

Mas o leitor pode estar pensando o que o Movimento Surdo tem a ver com a entrada de surdos na graduação e pós-graduação brasileira, ou, mais especificamente, o que ele tem a ver com a produção acadêmica de surdos. Ora, como veremos a seguir, por vezes toda essa mobilização social acaba por desaguar na universidade, lugar de reflexão e produção de conhecimento por excelência. Atualmente, sujeitos surdos graduam-se e 
ingressam em cursos de pós-graduação stricto sensu em número crescente, fazendo a discussão política gestada socialmente resplandecer na produção do conhecimento acadêmico produzido pelo grupo. Este artigo, pois, discute a necessidade de oferecimento de cursos de Letramento Acadêmico para esse público específico (graduandos e pósgraduandos surdos, constituídos por e pelo Movimento Surdo) e apresenta uma proposta possível.

\section{O surdo na universidade}

Devido, em grande medida, às políticas de expansão do ensino superior e a programas de apoio à inclusão educacional, surdos que há décadas mal podiam ler e escrever frequentam atualmente cursos de graduação, ingressam em programas de pósgraduação stricto-sensu e mobilizam pesquisas que contribuem para o avanço do conhecimento sobre sua língua, educação e cultura. Em nosso país, estima-se (RIBEIRO, 2008) que pelo menos quatro conquistas podem ter contribuído para a chegada dos surdos à universidade: a) a melhoria da educação básica oferecida aos surdos; b) a expansão do ensino superior; c) a politização das comunidades surdas e d) o reconhecimento acadêmicocientífico da Língua Brasileira de Sinais, seguido de sua regulamentação legislativa em âmbito nacional.

Em linhas gerais, de maneira bastante reduzida, pode-se dizer que a primeira dessas conquistas está intimamente relacionada ao uso e à difusão da língua de sinais (LS) nas escolas, sejam elas inclusivas, especiais ou bilíngues ${ }^{2}$. O incremento consistente da LS nas escolas (sobretudo através do profissional intérprete) representou uma via de acesso ao conhecimento para os alunos surdos e proporcionou melhor aproveitamento/desenvolvimento de suas potencialidades intelectuais.

A segunda conquista foi possibilitada pelas políticas de expansão do acesso ao ensino superior, notadamente a partir do governo Lula (2003), representadas por programas de fomento tanto à iniciativa privada (Prouni e FIES) quanto à pública (Reuni), o que levou a um expressivo aumento do número de vagas disponíveis (BRASIL, 2015). Como cidadãos brasileiros, os surdos também se beneficiaram desses processos. A instauração e manutenção de cursos de graduação em Letras/Libras, idealizado pela UFSC e oferecido

\footnotetext{
${ }^{2}$ Outras conquistas poderiam ser citadas, como a atuação de instrutores surdos e de professores surdos ou bilíngues, como se verifica em muitas escolas. Contudo, considerando as dimensões continentais e as desigualdades de nosso país, ressaltamos que de norte a sul verificam-se diferentes formatos de "inclusão educacional", em relação aos surdos, assim como de escolas chamadas bilíngues.
} 
em dezoito polos pelo Brasil, por exemplo, se insere nesse momento histórico-educacional.

Somam-se a essas duas questões uma terceira: o fortalecimento político do povo surdo (letra 'c' acima). Mais conscientes de si e do mundo, os surdos descobriram-se apenas diferentes e rejeitam de vez o estigma de deficientes, como discutido aqui. Engajam-se em movimentos classistas pelo reconhecimento de sua língua e cultura minoritária e lutam contra formas de dominação e opressão impostas pela norma ouvinte, por meio do Movimento Surdo. Buscam-se graduar-se e, na academia, priorizam a produção de saberes afinados com a agenda do Movimento no intuito de proporcionar autonomia, reconhecimento e melhorias linguísticas, educacionais e sociais para os seus.

E, por fim, todas essas conquistas têm sido legitimadas por duas ações: primeiro, por um movimento acadêmico de descrição linguística da Língua Brasileira de Sinais (em ocorrência principalmente no Instituto Nacional de Educação de Surdos (INES), na USP, UFSC, UnB e, mais recentemente, na UFG) - dado que valida o seu valor enquanto língua natural humana e, em segundo lugar, pela regulamentação legislativa da Libras em âmbito nacional (letra 'd'), pois, como se sabe, a lei 10.436/2002 (BRASIL, 2002), regulamentada pelo decreto 5.626/2005 (BRASIL, 2005), reconhece a Língua Brasileira de Sinais como o meio legal de comunicação e expressão do surdo brasileiro.

Nesse cenário de conquistas e recentes favorecimentos, é possível perguntar: por que só muito recentemente surdos começaram a frequentar a universidade? Ora, sabe-se que em nosso país, foi necessário sancionar uma lei reconhecendo a Libras como meio legal de comunicação do surdo brasileiro, para que surdos sinalizadores começassem a ser aceitos com a considerada exoticidade de sua língua. Antes disso, apesar de todos os avanços e pesquisas relativas à Língua Brasileira de Sinais e à educação de surdos, o que se observava era a pouquíssima crença ou atenção conferida às pessoas surdas. Após a sanção da lei, contudo, a discussão sobre o povo surdo (sua língua, cultura e educação) cresceu e, junto com ela, o número de vagas nas escolas, não apenas para surdos, mas também para intérpretes de Libras, em decorrência das políticas públicas de inclusão que garantem, por exemplo, a presença do tradutor/intérprete de Libras em concursos públicos, ainda que essa norma não seja totalmente cumprida nas/pelas instituições. Portanto, apesar de o número de surdos universitários no Brasil ainda ser provavelmente baixo, não podemos nos esquecer de que ele é historicamente significativo.

Atualmente, no Brasil, há relatos de pós-graduandos surdos em diversas universidades públicas e privadas. É possível citar a Universidade de Brasília, a Universidade Federal de Santa Catarina e a Universidade Federal do Rio Grande do Sul Olh@res, Guarulhos, v. 4, n. 1, p. 269-286, maio 2016. 
como as que mais se destacam na formação de recursos humanos surdos na pós-graduação, até o momento. Vê-se, por exemplo, que atualmente, através da implantação de uma política de cotas para surdos, o Programa de Pós-Graduação em Linguística (PGL) da UnB conta com 09 (nove) surdos mestrandos e 03 (três) surdos doutorandos, além de já ter outorgado título de Mestre a 06 (seis) outros estudantes surdos ${ }^{3}$.

O gráfico abaixo, extraído de Vilhalva (2010, p. 02), ilustra a aprovação de surdos em programas de pós-graduação antes e após a publicação da referida lei 10.436/2002 e decreto 5.626/2005. Antes dela, o percentual era insignificante. Nos anos posteriores ao decreto (de 2005 a 2010), constata-se um crescimento significativo e, em 2010, um salto surpreendente, pois o número de surdos na pós-graduação representa mais da metade do acumulado entre 2005 e 2010, fato que não deixa dúvidas quanto ao ingresso, cada vez maior, de surdos na pós-graduação stricto sensu:

Gráfico 1: Surdos em Programas de Pós-Graduação

\section{Surdos aprovados em Programas de Pós-Graduação antes e após a Lei 10436/2002 e o Decreto 5626/2005}

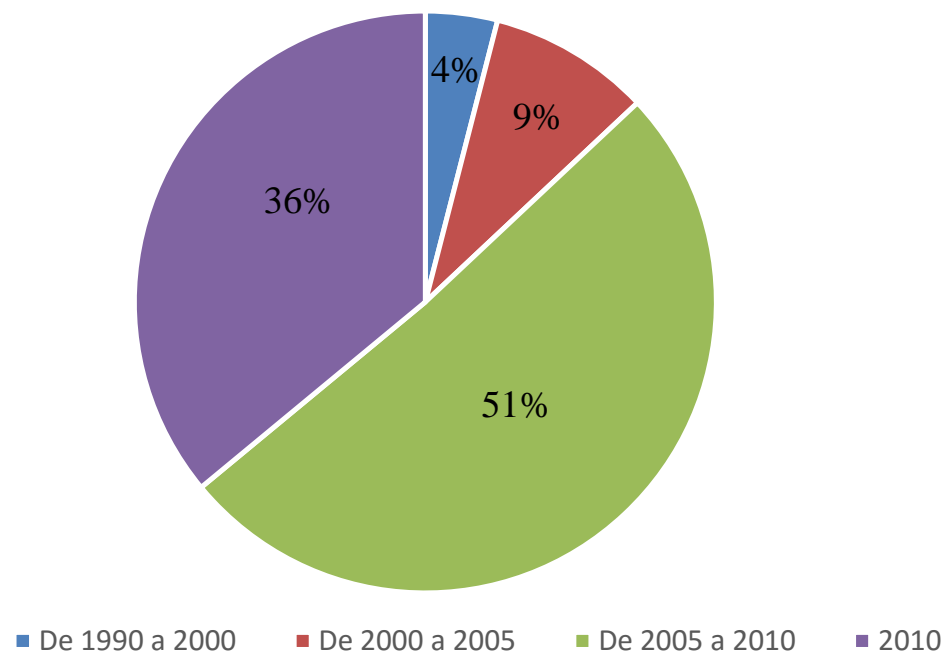

Fonte: Vilhalva (2010, p. 02).

Neste artigo, interessa-nos pensar na garantia da permanência desses sujeitos na graduação, mas sobretudo na pós-graduação brasileira e na qualidade do produto decorrente dessa entrada, focalizando os meandros da constituição discursiva da produção acadêmica empreendida por surdos. A seguir, discutem-se brevemente características da produção acadêmica de autoria surda para, seguidamente, apresentar tópicos de uma

\footnotetext{
${ }^{3}$ Dados obtidos junto à secretaria do Programa de Pós-Graduação em Linguística em maio de 2014.
} 
proposta de Letramento Acadêmico para surdos.

\section{A produção acadêmica de surdos}

De maneira geral, na pós-graduação, surdos discutem problemas relacionados à sua própria língua, educação e cultura. Discutem por uma ótica inovadora porque interna. Não se trata mais do ponto de vista do outro sobre o "dominado", mas das proposições e visões nascidas em meio à dominação, derivadas de vivências conhecidas na pele. Por essa razão, sujeito e objeto, nas pesquisas empreendidas por surdos, não encarnam instâncias neutras e distantes, mas continuidades de uma mesma entidade (RIBEIRO, 2012).

Boaventura de Sousa Santos (2005) considera a relação de proximidade entre o sujeito da pesquisa e o objeto pesquisado como característica da ciência pós-moderna, que rompe com o paradigma de racionalidade científica herdado no século XVI. Neste cenário, interessa-nos pensar nos desdobramentos dessa relação na pesquisa de autoria surda e, mais especificamente, na configuração discursiva do texto a ser a produzido a partir dela.

O racional (consciente ou inconsciente) que se vê traçado nas atividades de pesquisa empreendidas por surdos, é algo como a seguinte reflexão: se a produção do conhecimento é desenvolvida a partir de uma ótica interna ao problema pesquisado e se os sujeitos que o fazem têm histórico de opressão e dominação ouvintes, além de recente atuação no Movimento Surdo; se se sabe que o conhecimento é uma via de acesso para transformações sociais de todas as ordens e a forma mais prestigiosa e respeitosa de se fazer ouvido, por que não trazer as agendas de luta do Movimento Surdo para dentro da academia?

Vemos, assim, em boa parcela das pesquisas produzidas por surdos, a impossibilidade do sujeito da pesquisa exilar-se do sujeito que milita em uma causa social própria, de tal maneira que duas vozes podem ser percebidas nas referidas pesquisas: a do sujeito que pesquisa, gere e administra um fazer acadêmico, com as normas e coerções próprias ao gênero textual e lugar institucional, e a do sujeito surdo que se envolve com os anseios e posicionamentos relativos à agenda de reivindicações de um fazer ativista social (RIBEIRO, 2012).

Apesar de tal relação caracterizar com propriedade a pesquisa acadêmica de surdos, ela também se faz presente na atividade acadêmica de outras minorias, como negros ou homossexuais, por exemplo (MAMA, 2010). Fora desses grupos, nas humanidades, vemos ainda alguns setores da Educação, da Sociologia e da Linguística produzirem Olh@res, Guarulhos, v. 4, n. 1, p. 269-286, maio 2016. 
pesquisas com algum valor de engajamento, com diferentes graus de assunção e explicitude.

Ora, mas ainda em pesquisas que não sejam explicitamente engajadas, sabe-se que o sujeito empírico que está por trás de toda elaboração acadêmico-científica é um sujeito que inevitavelmente sente, interpreta e faz escolhas. Além disso, o instrumento essencial que possibilita o fazer acadêmico-científico - a própria linguagem - permite entender que o discurso (também subjetivo) da ciência é alicerçado por um fazer persuasivoargumentativo e, portanto, passível de manobras discursivas não dogmatizadas e moldadas pela subjetividade do sujeito produtor, como sustenta Coracini (1991). Tem-se ainda que a ciência não é a encarnação de uma verdade, mas uma explicação provisória e parcial da realidade, que pode, no entanto, criar um efeito de sentido de verdade, como nos lembra Fiorin (1988). É nessa perspectiva que Boaventura de Sousa Santos (2005) postula a necessidade de um saber científico de bem não apenas com o sujeito produtor, mas também com a coletividade que ele representa.

Nas pesquisas empreendidas por surdos, como se sabe, o engajamento se faz notório e sua assunção é claramente manifesta. Para ilustrar esse fato, constam, no quadro a seguir, dados de três teses de doutorado em Educação, produzidas por surdos, que retratam de maneira significativa a relação de sobreposição de fazeres (acadêmicos e ativistas) aqui delineada:

Quadro 01: Teses produzidas por surdos

\begin{tabular}{|l|c|c|c|c|}
\hline \multicolumn{2}{|c|}{ Tese } & Autor & Instituição & Ano \\
\hline 1 & $\begin{array}{c}\text { Implante Coclear na constituição } \\
\text { dos sujeitos surdos } \\
\text { Doutorado em Educação }\end{array}$ & $\begin{array}{c}\text { REZENDE, } \\
\text { Patrícia L. } \\
\text { Ferreira }\end{array}$ & UFSC & 2010 \\
\hline \multirow{3}{*}{2} & $\begin{array}{c}\text { Surdos: vestígios culturais não } \\
\text { registrados na História. }\end{array}$ & $\begin{array}{c}\text { STROBEL, } \\
\text { Karin Lílian }\end{array}$ & UFSC & 2008 \\
& $\begin{array}{c}\text { Doutorado em Educação. } \\
3\end{array}$ & A Experiência e a Pedagogia que & MIRANDA, \\
nós surdos queremos & Wilson & UFRGS & 2007 \\
& Doutorado em Educação & Oliveira & & \\
& & & & \\
\hline
\end{tabular}

Fonte: elaboração própria 
A primeira tese enfrenta o império do Implante Coclear ${ }^{4}$ com o objetivo de fazer frear a voracidade dos discursos sobre sua introdução na vida dos surdos ou, pelo menos, com o objetivo de fazer a Língua Brasileira de Sinais sobreviver (ou entrar) nos espaços já dominados por ele. Defende que a tentativa de "reparar" a surdez é um esforço de controle, normalização e disciplinamento da sociedade ouvinte sobre os surdos.

A tese 2, por sua vez, denuncia histórias de horrores (maus tratos, abusos e opressões) vivenciadas por surdos numa época em que esses ainda estavam fortemente subjugados ao domínio de instituições escolares ouvintistas. Relata agressões físicas e morais jamais registradas oficialmente, caracterizando o passado recente da comunidade surda como dominado por forças opressoras. Dirige-se, sobretudo, ao povo surdo, interlocutor modelo da tese, no intuito de alertá-lo sobre a precariedade do passado e incitá-lo a reescrever, com atitudes outras (políticas e participativas), o futuro.

Já a tese 3 objetiva fazerem ouvidas as intervenções pedagógicas esperadas e produzidas pelos próprios surdos sobre a educação que esperam receber. Traz à tona o fato de que a educação de surdos, historicamente, foi pensada pelos ouvintes, e que a "pedagogia surda" precisa ser ouvida. A tese dá voz a pedagogos surdos e propõe a educação que "nós surdos queremos", produzida por surdos e para surdos.

As pesquisas acima fornecem indícios de que gerenciar, no fio do discurso, as facetas "sujeito surdo pesquisador" e "sujeito surdo militante", é uma tarefa que impõe tensões de múltiplas ordens. O trecho a seguir, por exemplo, retirado da tese 01 , relata momentos angustiantes e de lutas internas ocorridas à época da elaboração da tese de doutorado, vejamos:

\footnotetext{
Foram muitos os momentos em que precisei fugir da militância, emergir dos "mergulhos militantes" da causa e dos movimentos surdos, para poder dialogar com Foucault, que pede o distanciamento da militância no mergulho das problematizações que fiz ao longo desta tese. Foram momentos sofridos. Muitas palavras e pensamentos foram apagados das páginas dessa produção por conter conteúdos militantes. Fiz o que era possível para analisar, problematizar e dialogar com Foucault. Ele me fez entender que, mesmo estando enredada pelas práticas sociais e jogos de poder/saber e imersa nos muitos discursos e saberes da norma ouvinte e da norma surda, eu posso me vigiar e ser um sujeito que olha e diagnostica as práticas do seu tempo e espaço. O tempo e o espaço do mundo surdo.

(...) Travei, no meu interior, um forte embate, pois, a todo tempo, precisei fugir das armadilhas impostas pela militância. Foi uma vigilância constante para não cair no abismo teórico de uma tese (REZENDE, 2010, p. 157).
}

\footnotetext{
${ }^{4} \mathrm{O}$ implante Coclear é uma tecnologia (um implante interno) que promete reverter a surdez.
}

Olh@res, Guarulhos, v. 4, n. 1, p. 269-286, maio 2016. 
O trecho acima mostra que estamos diante de uma questão bastante complexa, que se relaciona ao gerenciamento de vozes e posicionamentos (do sujeito pesquisador e do sujeito ativista) no discurso acadêmico.

O tratamento desta questão em um curso de Letramento Acadêmico para surdos não pretende, obviamente, abafar a voz ativista e superdimensionar a acadêmica, mas, precisamente, entender o modo de tessitura que convém a cada esfera de produção e a cada empreendimento em questão. Acredita-se que levar a relação ativismo social e produção de conhecimento a ser claramente discutida, favorecendo o gerenciamento consciente desses fazeres, é uma atitude que produzirá melhores frutos tanto para a academia quanto para o Movimento Surdo. Há pesquisas, por exemplo, que por diversas razões, podem se mostrar alheias às discussões linguístico-educacionais mais significativas empreendidas pela comunidade surda. Discutir, portanto, junto a tais pesquisadores, os valores e efeitos envolvidos e decorrentes de pesquisas acadêmicas pode representar um ganho de maturação tanto acadêmica quanto político-social.

Nesse sentido, discutir as funções e papeis de cada faceta (acadêmica e ativista) no empreendimento acadêmico junto aos surdos é tarefa que precisa ser assumida ou pelos professores que orientam pós-graduandos surdos, e/ou por um professor específico, de uma disciplina particular, que possibilite certo grau de Letramento Acadêmico a esses sujeitos. Essa discussão poderia partir de sociólogos como Santos (2005) e Bourdieu (2003), por exemplo, em conjunção com a discussão sobre os propósitos acadêmicos e metodológicos de cada gênero da esfera acadêmica (ECO, 1992; DUSZAK, 1997; HAYLAND; BONDI, 2006; ARAÚJO, 2006). É a partir da discussão e vivência coletiva que pós-graduandos surdos entenderão os modus operandi dos discursos acadêmicos e as formas de inserção de discursos ativistas. O que este estudo defende, portanto, é que a relação pesquisa acadêmica e ativismo social não seja tomada como tabu, mas que seja ampla e claramente discutida.

Junto a essa discussão, pós-graduandos surdos precisam ainda de reforços extras no que tange às práticas de leitura e escrita da língua portuguesa na esfera acadêmica. Oriundos de uma tradição escolar oralista que deixou sequelas notáveis na relação sujeito surdo/língua portuguesa - além do fato natural de que usuários (sobretudo estrangeiros) de dada língua estarem sempre no lugar de aprendizes - seria preciso, pois, abordar pragmaticamente conteúdos relacionados à variedade padrão da Língua Portuguesa utilizada em discursos acadêmicos, uma vez que muitos são os relatos, em trabalhos acadêmicos produzidos por surdos, de dificuldades vivenciadas com a Língua Portuguesa, 
como ilustra o trecho a seguir:

\begin{abstract}
No referencial metodológico, a palavra viva destas experiências foi primeiramente captada pela filmagem, e depois foi transcrita a fim de tornar possível uma primeira passagem da Língua de Sinais para o escrito. Trabalhei o material escrito para que se fundisse num verdadeiro texto, um texto a minha própria mão e minha mente onde coabitasse dois "idiomas", duas maneiras singulares de se exprimir numa língua da fronteira ${ }^{1}$ (MIRANDA, 2007, p. 01).

\footnotetext{
${ }^{1}$ São duas maneiras de se exprimir numa língua de fronteira pois: o primeiro o português é limitado, a segunda a Língua de Sinais também é limitada pelo compromisso de me fazer entender ao intérprete e ao leitor.
}

Neste trecho, o autor da tese 3 expõe a (con)fusão entre línguas e culturas que está presente em seu texto: o português é considerado "língua de fronteira" e certamente haverá desdobramentos advindos daí. A expressão linguística do sujeito é relatada como sempre limitada, seja porque, no português, o "estrangeirismo", ou seja, o fato de ser nativo de outra língua, o coloca como eterno aprendiz de uma língua que ele só apre(e)nde através da escrita e da leitura, seja porque, expressando-se em Libras, sua língua materna, haverá sempre "estrangeiros" que precisam compreendê-lo: os intérpretes e os leitores que, provavelmente, receberam uma reflexão originalmente elaborada (mentalmente) em sinais, embora apresentada em português. A tessitura dos fios discursivos de muitas pesquisas empreendidas por surdos, portanto, parece ser composta tanto pela língua portuguesa (L2) quanto pela língua de sinais (L1), apesar de apenas a primeira estar evidenciada.

Essa tensão constitui o modo surdo de se dizer o português e deve ser contemplada em um dos eixos de ensino que venham a compor uma proposta de Letramento Acadêmico para Surdos, como veremos a seguir.

\title{
Por uma proposta de letramento acadêmico para surdos
}

Levando em consideração a história de opressão linguística vivenciada por sujeitos surdos; a notória organização do grupo em torno do chamado Movimento Surdo; o recente ingresso da comunidade no ensino superior e na pós-graduação e a produção de conhecimento acadêmico dotado de engajamento social, apresentam-se, a seguir, eixos norteadores de uma proposta de letramento acadêmico para surdos. 
Cursos de Letramento Acadêmico para surdos poderiam ser pensados tanto em nível nacional, via plataforma Moodle ${ }^{5}$, a exemplo do que acontece com os cursos da Universidade Aberta do Brasil, ou preferencialmente reformulado nas diversas universidades que têm surdos matriculados em programas de pós-graduação. A presente proposta apresenta quatro eixos estruturantes: i) eixo das atividades acadêmicas e das atividades ativistas; ii) eixo do gerenciamento de vozes; iii) eixo normativometodológico; iv) eixo da estrutura da língua portuguesa. Esta elaboração parte do conhecimento da produção acadêmica de surdos adquirida em pesquisa de doutoramento (RIBEIRO, 2012) e da escuta de relatos de angústias e inquietações vivenciadas por surdos no desenvolvimento de pesquisas acadêmicas.

Até o momento, não há notícias de cursos de português para surdos voltados especificamente para o desenvolvimento de habilidades de escrita acadêmica e, ao mesmo tempo, para o gerenciamento das facetas acadêmica e ativista-social no fio do discurso. Para se pensar nos alicerces dessa empreita considerada inédita, portanto, de início, é preciso expor sumariamente as características da produção acadêmica surda para, em seguida, propor tópicos pertinentes a um programa básico.

A experiência, tanto empírica quanto acadêmica (RIBEIRO, 2012), tem mostrado até o momento que:

1. A produção acadêmica cunhada por surdos costuma ser representante autêntica de um modelo de racionalidade científica emergente, que relaciona ao fazer acadêmico um fazer militante ou ativista-social (RIBEIRO, 2012), como já exposto. A partir daí, o eixo das facetas acadêmicas e ativistas-sociais poderia discutir as tensões entre poder, produção de conhecimento e autoconhecimento coletivo, uma vez que o desafio é formar essa nova geração de pesquisadores surdos a partir de um processo identitário que abarque, ao mesmo tempo, a complexidade do ser surdo no mundo da produção científica e no mundo da vivência comunitária, instruindo jovens surdos, por um lado, sobre as contribuições do fazer ativista na academia mas, por outro, sobre os limites de ação da faceta militante no interior do discurso acadêmico-científico. Conforme comentários anteriores, essa discussão poderia partir de sociólogos como Santos (2005) e Bourdieu (2003), por exemplo, em conjunção com a discussão sobre os propósitos acadêmicos e

\footnotetext{
${ }^{5}$ Sabbatine (2016, p. 1) define o Moodle como "uma plataforma de aprendizagem a distância baseada em software livre. É um acrônimo de Modular Object-Oriented Dynamic Learning Environment (ambiente modular de aprendizagem dinâmica orientada a objetos)". A plataforma oferece possibilidades de armazenamento de dados e interações entre participantes, entre outros recursos.
} 
metodológicos de cada gênero da esfera acadêmica (ECO, 1992; DUSZAK, 1997; HAYLAND; BONDI, 2006; ARAÚJO, 2006).

2. A posição linguístico-cultural do sujeito surdo frente à produção de discursos acadêmicos em Língua Portuguesa acaba por gerar uma série de processos discursivos regidos pela tensão sujeito/língua. Por se posicionar como usuário "estrangeiro" da Língua Portuguesa, há uma série de habilidades e estratégias a serem urgentemente ensinadas aos surdos. O Eixo do gerenciamento de vozes poderia incluir, por exemplo, desde o ensino da produção de resumos, resenhas e paráfrases até de procedimentos citatórios e estratégias de apresentação de vozes alheias, entrecortadas pela voz do sujeito que escreve. Uma vez que a tensão sujeito/língua tem feito crescer nos surdos o desejo de produzir suas dissertações e teses em Língua Brasileira de Sinais - questão certamente polêmica, se se pensar que surdos precisam, sim, dominar o instrumento de prestígio e poder que é a Língua Portuguesa - é preciso, pois, incluir ainda nesse eixo discussões relativas às funções, ao papel e à importância dessa língua na vida dos surdos, principalmente àqueles voltados para atividades acadêmicas ${ }^{6}$. Obras como a de Perrota (2004) ou a coleção coordenada por Anna Rachel Machado, por exemplo, mostram-se pertinentes pela vantagem de ensinar jovens escritores a reportarem a voz do outro ou sustentarem a sua própria voz (MACHADO; LOUSADA; ABREU-TARDELLI, 2004).

3. Uma vez que normalmente a posição de sujeito pesquisador é a mais recente para o sujeito, se comparada à sua suposição de ser social/ativista/militante na causa/Movimento Surdo, naturalmente, a normatização do modo de se fazer e comunicar pesquisas na academia se mostra como uma novidade a ser internalizada. Ainda que esse sujeito tenha passado, como os demais (não surdos), pela graduação, não se pode perder de vista que a sua posição de usuário nativo da Libras (e estrangeiro da língua portuguesa) o coloca em um lugar de alguma maneira desprivilegiado no processo de aquisição de normas metodológicas em relação aos outros, usuários nativos e íntimos do português. Propõe-se, assim, que no Eixo normativo-metodológico, se discuta o desenvolvimento de gêneros acadêmicos diversificados, onde se discutiria desde a delimitação e função das seções que compõem os gêneros acadêmicos artigos, dissertações e teses, até os meios de composição estrutural das citações e referências, por exemplo.

4. E, por fim, não se pode deixar de contemplar o ensino da língua portuguesa

\footnotetext{
${ }^{6}$ Propõe-se discutir o papel e importância da Língua Portuguesa para o cidadão surdo neste eixo (e não, especificamente, no eixo da Estrutura da Língua Portuguesa), porque se considera este um problema de percepção, muito mais do que de estruturação.
}

Olh@res, Guarulhos, v. 4, n. 1, p. 269-286, maio 2016. 
formal escrita como uma atitude de empoderamento dos sujeitos. Apesar de ser crescente o desejo de surdos produzirem Trabalhos de Conclusão de Curso em Língua Brasileira de Sinais, como dito, é inquestionável a necessidade crescente dos sujeitos dominarem cada vez mais a Língua Portuguesa padrão na modalidade escrita (tanto para ter acesso ao patrimônio intelectual produzido nesta língua quanto para contribuir com ele). A partir de uma abordagem não opressora, mas sim libertária, este eixo visa desenvolver habilidades de coesão e coerência textual, assim como de estruturação e correção linguística.

O diferencial de um curso de Letramento Acadêmico para Surdos, além das especificidades dos eixos norteadores, é que se supõe um professor bilíngue, elaborando e ministrando aulas em sinais, para uma turma composta exclusivamente por surdos (pósgraduandos e, eventualmente, graduandos envolvidos em projetos de Iniciação Científica). Essa configuração determina um funcionamento totalmente específico para a sala de aula, regido pela premissa máxima que tudo altera e determina: o fato da língua portuguesa ser a segunda língua dos alunos envolvidos. Assim, currículos, conteúdos e metodologias também são regidos por essa premissa.

\section{Considerações Finais}

Especializar-se é fenômeno moderno. Mas quando se pensa em sujeitos surdos, parece haver um fenômeno pós-moderno à espera de compreensão: sujeitos que já foram vistos como incapacitados intelectualmente - e que foram considerados privados do uso da faculdade da linguagem - têm contribuído para o avanço da ciência e do saber sobre si mesmos.

$\mathrm{Na}$ universidade, para que possamos fomentar a entrada de surdos, garantir a permanência, incentivar a qualidade e manter a escuta, precisamos criar zonas de conforto no encontro sujeito/língua portuguesa na esfera do discurso acadêmico. Zonas de atrito sujeito/língua foram criadas durante todo o percurso escolar desses sujeitos e não podemos deixar que isso se repita, além do previsto, na pós-graduação.

Neste artigo, discutiu-se a necessidade do oferecimento de cursos de Letramento Acadêmico para surdos e se delineou uma primeira proposta de trabalho com o objetivo de inspirar atitudes que focalizem esse problema. Buscar meios para fomentar as habilidades de leitura e escrita acadêmica de (pós)-graduandos surdos é uma atividade que deve ser assumida pela universidade como tão necessária quanto possível. Os ganhos dessa empreita se distribuem a todos: universidade, orientadores, surdos e sociedade civil. 


\section{REFERÊNCIAS BIBLIOGRÁFICAS}

Dall’ALBA, C. D. Movimento surdo no cenário contemporâneo. In: I Encontro Nacional de Libras - PUC/RS. Porto Alegre. Disponível em:

$<$ http://www.porsinal.pt/index. php?ps=artigos\&idt=artc\&cat=19\&idart=166 >. Acesso em: 20 ago. 2012.

ARAUJO, A. D. Práticas discursivas em conclusões de teses de doutorado. Linguagem em (dis)curso, v. 6, n. 3, 2006. Disponível em:

$<$ http://www.portaldeperiodicos.unisul.br/index.php/Linguagem_Discurso/article/view Article/345>. Acesso em: 05 set. 2013.

BOURDIEU, P. Os usos sociais da ciência. Por uma sociologia clínica do campo científico. São Paulo: Editora Unesp, 2003.

BRASIL. Lei 10.436, 22 de abril de 2002. Disponhõe sobre a Língua Brasileira de Sinais - Libras e dá outras providências. Disponível em:

<http://www.planalto.gov.br/ccivil_03/leis/2002/L10436.htm> Acesso: abr. 2016.

BRASIL. Decreto 5.626/2005, de 22 de dezembro de 2005. Regulamenta a Lei $\mathrm{n}^{\mathrm{O}}$ 10.436, de 24 de abril de 2002, que dispõe sobre a Língua Brasileira de Sinais Libras, e o art. 18 da Lei ${ }^{\circ} 10.098$, de 19 de dezembro de 2000. Disponível em: <http://www.planalto.gov.br/ccivil_03/_ato2004-2006/2005/decreto/d5626.htm>. Acesso: Abril de 2015.

BRASIL. A democratização e expansão da educação superior no país 2003 - 2014. Relatório da Secretaria de Educação Superior. Ministério da Educação, 2015.

Disponível em

<http://portal.mec.gov.br/index.php?option=com_docman\&view=download\&alias=167 62-balanco-social-sesu-2003-2014\&Itemid=30192>. Acesso: março de 2015.

CORACINI, M. J. R. F. Um fazer persuasivo: o discurso subjetivo da ciência. Campinas, SP: Pontes, 1991.

DUSZAK, A. Cross-cultural academic communication: a discursive-community view. In: Culture and styles of academic discourse. New York: Mouton de Gruyter, 1997.

ECO, H.. Como se faz uma tese. São Paulo: Perspectiva, 1992.

FIORIN, J. L. O regime de 1964: discurso e ideologia. São Paulo: Atual, 1988.

HAYLAND, K.; BONDI, M. Academic discourse across disciplines. Bern: Peter Lang, 2006.

LEA, M. R.; STREET, B. Student Writing in higher education: an academic literacies approach. In: Studies in Higher Education. London, v. 23, n. 2, June, 1998, p. 157168.

LODI, A. C. B. Uma leitura enunciativa da Língua Brasileira de Sinais: o gênero contos de fadas. DELTA. Documentação de Estudos em Linguística Teórica e Aplicada, São Paulo, v. 20, n. 2, p. 281-310, 2004. Disponível em: <http://www.scielo.br/pdf/delta/v20n2/24271.pdf>. Acesso: 10 maio 2010.

MACHADO, A. R.; LOUSADA, E.; ABREU-TARDELLI, L. S. Resumo. São Paulo: Parábola, 2004. 
Resenha. São Paulo: Parábola, 2004.

MAMA, A. Será ético estudar a África? Considerações preliminares sobre pesquisa acadêmica e liberdade. In: SANTOS, B. S.; MENEZES, M. P. (orgs.) Epistemologias do Sul. São Paulo: Cortez, 2010, p. 603-637.

MIRANDA, W. O. A experiência e a pedagogia que nós surdos queremos. 2007. 153 f. Tese (Doutorado em Educação). Faculdade de Educação. Universidade Federal do Rio Grande do Sul, Porto Alegre. 2007. Disponível em:

<http://www.lume.ufrgs.br/bitstream/handle/10183/13581/000645759.pdf? sequence=1> . Acesso em: ago. 2009.

PERROTA, C. Um texto para chamar de seu: preliminares sobre a produção do texto acadêmico. São Paulo: Martins Fontes, 2004.

RANGEL, M. A Diversidade e a Reivindicação de direitos nos Movimentos Sociais. Revista da FAEEBA - Educação e Contemporaneidade, Salvador, v. 19, n. 34, p. 39-47, jul./dez. 2010. Disponível em:

<http://www.uneb.br/revistadafaeeba/files/2011/05/numero34.pdf $>$. Acesso: 15 de julho de 2013.

REZENDE, P. L. F. Implante Coclear na constituição dos sujeitos surdos. $164 \mathrm{f}$. Tese (Doutorado em Educação). Faculdade de Educação. Universidade Federal de Santa Catarina, Florianópolis, 2010. Disponível em:

$\langle$ http://repositorio.ufsc.br/bitstream/handle/123456789/8545/281476.pdf?sequence=1 > Acesso em: jan. 2011.

STREET, B. V. Literacy in theory and practice. London: Cambridge University Press, 1984.

STROBEL, Karin Lílian. Surdos: vestígios culturais não registrados na história. 2007. 176 f. Tese (Doutorado em Educação). Faculdade de Educação. Universidade Federal de Santa Catarina, Florianópolis, 2006. Disponível em:

<http://www.ronice.cce.prof.ufsc.br/index_arquivos/Documentos/karinstrobel.pdf>. Acesso em: maio 2009.

RIBEIRO, M. C. M. de A. O discurso acadêmico-científico produzido por surdos: entre o fazer acadêmico e o fazer militante. 2012. $262 \mathrm{f}$. Tese (Doutorado em Estudos Linguísticos). Faculdade de Letras. Universidade Federal de Minas Gerais, Belo Horizonte, 2012.

A escrita de si: discursos sobre o ser surdo e a surdez. $2008.186 \mathrm{f}$. Dissertação (Mestrado em Estudos Linguísticos). Faculdade de Letras. Universidade Federal de Minas Gerais, 2008.

SABBATINE, R. M. S. Ambiente de Ensino e Aprendizagem via Internet: a Plataforma Moodle. Instituto EduMed, 2016. Disponível em $<$ http://www.ead.edumed.org.br/file.php/1/PlataformaMoodle.pdf>. Acesso: abril de 2016.

RIBEIRO, M. C. M. A; LARA, G. M. P. O eu e o outro no campo discursivo da surdez. Estudos Semióticos. [on-line]. Vol. 6, n. 2, São Paulo, nov. 2010, p. 55-65. Disponível em: 〈http://www.revistas.usp.br/esse/article/view/49271>. Acesso em 30 ago. de 2014. 
SANTOS, B. S. Um discurso sobre as ciências. 13. ed. Porto: Afrontamento, 2005.

STOKOE, W. Sign language structure: an outline of the visual communication system of the American deaf. Studies in Linguistics: Occasional Papers, n.08, 1960.

VILHALVA, S. Trajetória Política dos Surdos no Brasil: Aprovação em concursos públicos e pós-graduação: Mestrado e Doutorado antes e depois da Lei 1.0436/2002 e do Decreto 5.626/2005. In: XI Congresso Internacional e XVII Seminário Nacional do Instituto Nacional de Educação de Surdos. Anais, 2010. Disponível em: <www.ines.gov.br/cienciaetecnologia/arquivos/anais2010.pdf>. Acesso em: 12 ago.2012.

Recebido em: 22/01/2016

Aprovado em: 10/05/2016 